This chapter engages with a discussion on the role of transport

mobility in the wellbeing of low-income urban citizens of the

Global South. Using the case of Abuja, Nigeria's capital city, we

explore transport-related vulnerabilities and disadvantages for lowincome and vulnerable groups and how they are addressed by local transport. First, the chapter aims to illustrate the importance of new knowledge(s) and methodologies critical to the future of transport planning in the Global South. Moving away from traditional measures of mobility, the chapter explores the potential of wellbeing as an operational concept in transport planning. By focusing on the different dimensions of wellbeing, a more rounded view of transport in the life of urban dwellers is developed, which leads transport planning down new avenues of knowledge and methodologies in the pursuit of more socially just cities. Second, in doing so, the chapter also seeks to reflect on what are essential mobilities and to explore the contribution of transport to achieve a quality of life that recognises the diverse identities of all urban citizens. The chapter showcases evidence of transport-related wellbeing in three dimensions: material, relational and subjective, 
9 Constructing wellbeing, deconstructing urban (im)mobilities in Abuja, Nigeria

building on information of daily travel practices, social and

cultural identities, socio-demographic characteristics and

subjective perceptions from low-income and vulnerable

populations. Such information was collected through quantitative

and qualitative instruments tailored to a conceptual framework for understanding personal wellbeing. Findings confront objective and subjective measures of wellbeing, suggesting added relevance of transport as either a potential enabler or constraint to personal autonomy and freedom, as well as the relevance of security and personal and collective expectations in defining the influence of transport policy in the lives of lower-income citizens. 
9

\title{
Constructing wellbeing, deconstructing urban (im)mobilities in Abuja, Nigeria
}

\author{
Daniel Oviedo, Caren Levy and Julio D Dávila
}

\section{Introduction}

The current crisis in mobility in most large cities of the Global South calls into question the entire traditional transport planning endeavour: its ideological underpinnings, its institutional framing and its methodological practices. The primary focus on private motorized vehicles, the speed/time measures of success and the development of transport provision in the interests of the few are obsolete in the face of widespread urban congestion and socio-spatial inequality. The links between congestion and inequality are complex, made up of the interaction between structural factors related to the political economy and socio-cultural processes, and urban practices related to governance, a range of planned interventions and the everyday struggle of urban citizens to live a decent life.

Addressing this crisis in physical and socio-economic terms requires rethinking some of the tenets of transport planning. This chapter is a contribution to this discussion in two ways. First, it aims to illustrate the importance of new knowledge(s) and methodologies critical to the future of transport planning in the Global South. Moving away from traditional measures of mobility, the chapter explores the potential of wellbeing as an operational concept in transport planning. By focusing on the different dimensions of wellbeing, a more rounded view of transport in the life of urban dwellers is developed, which leads transport planning down new avenues of knowledge and methodologies in the pursuit of more socially just cities. Second, in doing so, the chapter also seeks to reflect on what are essential mobilities and to explore the contribution of transport to achieve a quality of life that recognizes the diverse identities of all urban citizens.

This is explored in the case of Abuja, Nigeria's capital, and arises from a research project on transport in informal neighbourhoods in Abuja, Kaduna and Ibadan, three of Nigeria's largest cities. The research draws on primary qualitative information from semi-structured interviews and quantitative information from transport-user surveys collected in 2015 by a team from the 
Development Planning Unit (DPU), University College London (UCL), working with Nigerian partners. ${ }^{1}$

The focus on Abuja must be viewed in the context of urbanization and the development of planning before, during and after colonization in Nigeria. Linked to the development of powerful empires in the North and the South of the country in the eighteenth and nineteenth centuries, Nigeria has a long history of urbanization that pre-dates the colonial period (Mabogunje, 1968 in Solanke, 2013). Colonization brought with it new patterns of mobility because of accelerated urban growth and a change in spatial patterns associated with the development of roads and railways to serve the extractive practices of the colonial economy (exports of local natural resources such as minerals). Colonial approaches to urban development in the early twentieth century were largely predicated on 'the sanitation syndrome' (Swanson, 1977 in Mabogunje, 1992), a common impetus driving colonial administrations worldwide (on Bombay, India, see McFarlane, 2008). These early planning approaches were 'racist in orientation and segregationist in practice' (Mabogunje, 1992: 74) and in Nigeria developed into a three-sector division of cities, reflecting different degrees of intervention based on whether there were European settlement in cities or not (Home, 1983; Falola, 1996). The impact of that period was not only on the differential and unequal engagement with governance, the management of land and provision of infrastructure and housing in the development of particular cities, but also on urban development concentrated in a handful of cities that served the interests of the colonial economy (Falola, 1996).

With independence from Britain in 1960, the aspirations of the new Nigerian government were to address both the planning and management of cities, as well as to plan a national urban system that 'no longer serves the purpose of an outward-oriented colonial economy, which is less primate in its size distribution, and whose locational distribution within the national territory conduces to even development in the country' (Mabogunje, 1990: 146). Combined with a political determination to create a balanced federal system in such an ethnically diverse country, Nigeria went from three regional administrations in 1960 to 21 states by 1986. The capital cities of these states have served as nodes of high urban growth (Mabogunje, 1992; Home, 1983; Falola, 1996), where the interaction between urban development and the provision of road transport, particularly in peri-urban areas, has been important in the commodification of land and city expansion. Abuja enters the picture in 1976, when it was declared the new capital of Nigeria, a distinct federal capital territory of its own, planned around a modernist urban vision in a post-independence era.

In the next sections the definition of wellbeing as it relates to transport is discussed. This is followed by a more in-depth examination of transport and urban development in Abuja, and then a section drawing on research findings 
related to different dimensions of wellbeing and mobility in Abuja. The conclusions review the lessons learnt.

\section{Why wellbeing and transport mobility?}

\section{Rationale and definitions}

In urban settings in the Global South, lack of transport can become an obstacle to full participation in society, economic development and overall improvement in quality of life. Wachs (2010) argues that transport is central to poverty alleviation because it enables access to essential opportunities and social interactions. Poor households suffer measurable deficits in nutrition, health, education and opportunities to work, which are invariably correlated with deficits in mobility (Titheridge et al., 2014) and which are also often correlated with political marginalization. An intersectional view of poor households further highlights differential deficits on the basis of gender, age, disability and other social relations (Levy, 2013; Jones and Lucas, 2012; Oviedo and Titheridge, 2015). The built environments of cities in the Global South are characterized by their comparatively undeveloped road infrastructure, urban primacy and spatial inequalities (Cervero, 2013), which can restrict the ability of urban populations to appropriate the city and make full use of its opportunities. International agendas largely concerned with infrastructure development and mobility improvements have exacerbated environmental degradation and unequal distribution of opportunities arising from differences in the distribution of urban investments and people's capacity to travel (UN-HABITAT, 2013). Despite these challenges, large-scale transport interventions, often driven by technocratic approaches to urban planning and development, focus mostly on increasing speed of travel and maximizing passenger movement but rarely incorporate explicit aims such as social equity or increased wellbeing.

The notion of wellbeing is increasingly used to assess the impact of development policy (Boarini et al., 2006; Australian Government, 2010; and ONS, 2014). In many countries, there is a growing aspiration for incorporating wellbeing into policy goals and appraisal (Manderson, 2005). However, the multidimensional nature of the concept constrains its operationalization and feeds concerns on its validity for sector-specific assessments. In the face of these challenges, researchers tend to focus on specific dimensions and descriptions of wellbeing, making it difficult to reach conceptual and methodological agreements (Dodge et al., 2012; La Placa et al., 2013).

Transport has the potential to increase wellbeing through increased access to opportunities essential to lead a decent life, reduction in vulnerability to externalities and the promotion of active travel (i.e., walking and cycling) under appropriate conditions of safety and comfort. In cities of emerging economies, some of these objectives may be secondary in transport policy and 
development. There is the potential to integrate questions of wellbeing and inequality into transport policy and investment so as to more effectively redress transport gaps. And yet, despite contributions from different perspectives suggesting links between mobility and wellbeing, detailed examination of their relationships is relatively recent.

Definitions of wellbeing in transport research often focus on access to assets and connections required to meet needs, as well as on physical and mental health. Most conceptual and methodological advances have leaned towards health-related and subjective dimensions (Vella-Brodrick, 2011). This may have been influenced by a large body of research over the past 20 years that has dealt with issues such as accessibility, transport deprivation and social exclusion as part of the examination of the social dimensions of transport, (see Van Wee and Geurs, 2011; Jones and Lucas, 2012; Levy, 2013).

Research in industrialized societies analyzed the effects of mobility on the wellbeing of the elderly (Banister and Bowling, 2004; Mollenkopf et al., 2005; Spinney et al., 2009), with a more recent shift towards the effects of transport on notions such as connectedness, relatedness and satisfaction with life (Pacione, 2003; Delbosc and Currie, 2011; Stanley et al., 2011; VellaBrodrick, 2011). Evidence from recent research on transport disadvantage and transport-related social exclusion (Stanley and Lucas, 2008; Stanley and Vella-Brodrick, 2009; Delbosc and Currie, 2011; Vella-Brodrick and Delbosc. 2011) suggests that the mainstream goals of transport planning of connectedness and accessibility arise from an inadequate understanding of the relevance of transport in human life, pointing to wellbeing as the potential missing link in the development of transport policies and practices.

One of Nigeria's greatest challenges is to reconcile the policy objective of increasing the wellbeing of its citizens while seeking to promote economic growth, an aim that in many contexts has led to greater concentration of wealth and not necessarily to a concurrent reduction in poverty or improved wellbeing among the majority of the population. By linking multiple dimensions of wellbeing with urban transport, we intend to provide new empirical and conceptual elements to help inform this reconciliation into urban transport policy.

Under the premise that transport is a multidimensional construct, and building on empirical and conceptual evidence showing that mobility is an integral part of socio-economic and political disadvantage (Ohnmacht et al., 2009; Lucas, 2012), our research offers a framework to link transport and wellbeing. This is a person-centred framework, with three interdependent dimensions, material, relational and subjective, as shown in Figure 9.1. The material aspect of wellbeing encompasses the economic realm, but also incorporates elements of 'human capital' (Becker, 1962) such aseducation and health, as well as characteristics of the physical and natural environment. This dimension includes both the material assets required for attaining an adequate standard of living and the set of skills, abilities and environmental conditions 
to secure such assets and so be able to 'live well'. This approach to assessing the required assets and opportunities for a full life is strongly aligned with the concept of human development, which has governed recent development policy in the Global South. Human development is defined as the process of enlarging people's freedoms and opportunities and improving their wellbeing (UNDP, 1990). Such freedom encompasses the opportunities people have to decide who to be, what to do and how to live. The ideas around human development have shaped significant breakthroughs in international development policy that span from the publication of the report by Stiglitz et al., (2009) where they redefine economic and social progress, to the definition of the current Agenda for Sustainable Development for 2030 agreed in September 2015 at the General Assembly of the United Nations (van Lindert, 2016). This approach also provides ample space for freedom, which responds to the pluralism that defines the possible ways of living developed by every person in every context (Alkire, 2015).

The second dimension refers to the relational aspect of adequate living. Personal and social relations are central, incorporating social capital and relational experiences that contribute to a full life. This refers to relations of love and care and networks of support and obligation, the potential to develop social, political and cultural identities, and to take collective action within supportive governance structures, in the context of safety and security. The freedom to express these relates directly to the inherent feature of transport as public space, while other aspects of these elements involve complex social and personal characteristics where mobility may be less directly implicated than in the material dimension.

The third dimension relates to subjective perceptions, values and experiences (White, 2010). This is one of the most studied dimensions of wellbeing, arising from psychological literature (Vella-Brodrick, 2011). This encompasses perceptions of people's surroundings and their own life in a larger moral and social context, and also in a public and private spatial context that fosters the experience and expression of valued subjective characteristics. Wellbeing in this sense is often equated with 'happiness', leading to several indices aiming to measure life satisfaction and happiness as proxies to a full life (Camfield and Skevington, 2008).

\section{Methodological approach}

The methodological challenges of adapting this framework to transport involve producing tangible and interrelated evidence on the dynamic relations between the different dimensions of wellbeing and transport. We adopt a mixed methods approach to gathering evidence (see Figure 9.1). 


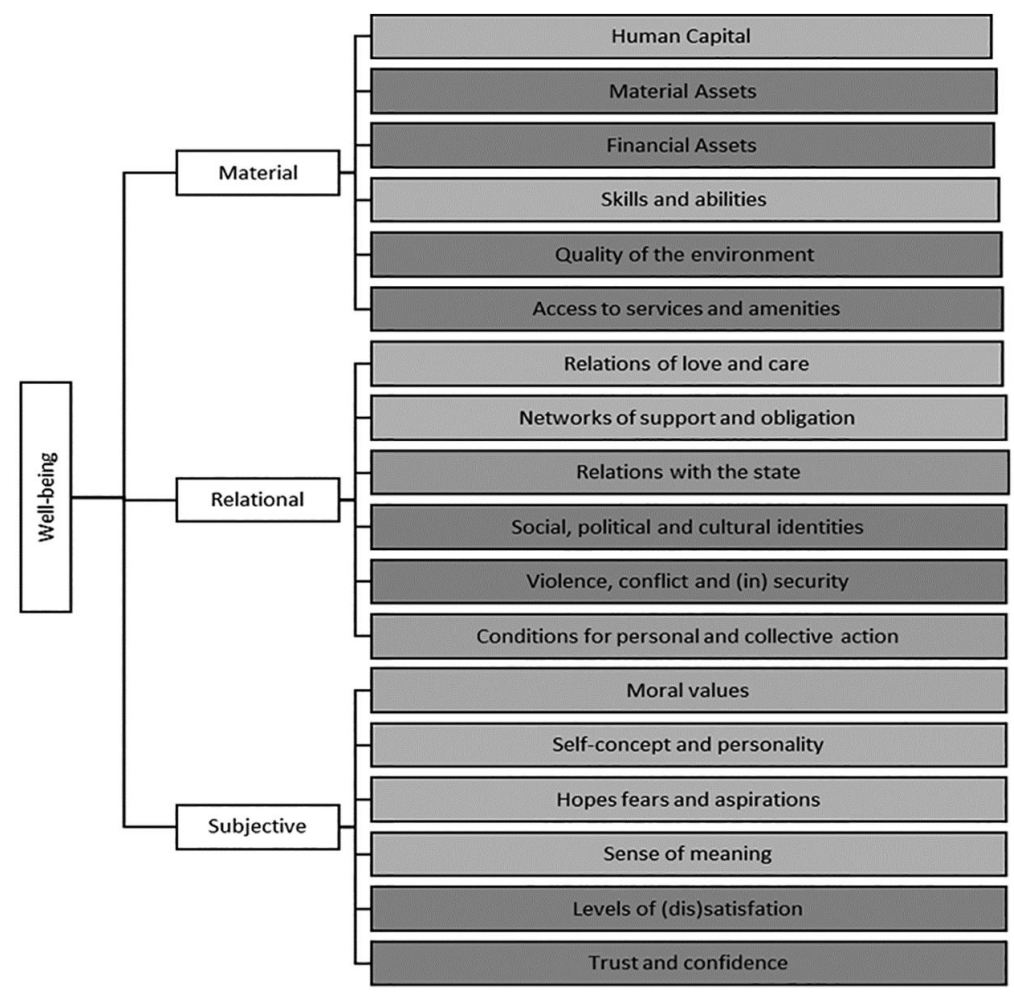

Quantitative evidence

Qualitative evidence

Mixed evidence

Figure 9.1 Transport and wellbeing: conceptual framework and type of evidence

Source: Own elaboration based on White (2010)

From a quantitative angle, data were collected through a field survey of 337 individuals in three low-income settlements in Abuja's metropolitan region (Jahi Village, Galadimawa and Kabusa - Figure 9.2). This involved an 'interception survey' whereby individuals waiting for transport services were approached with a set of questions. Doing this sought to: 1) identify commuters' residential location and demographical and socio-economic characteristics; 2) capture travel behaviour, travel choices and stated travel needs; and 3) identify perceptions of availability of transport choice, transport difficulties, access to activities and the impact of transport on quality of life and on accessing opportunities for economic and personal development. 


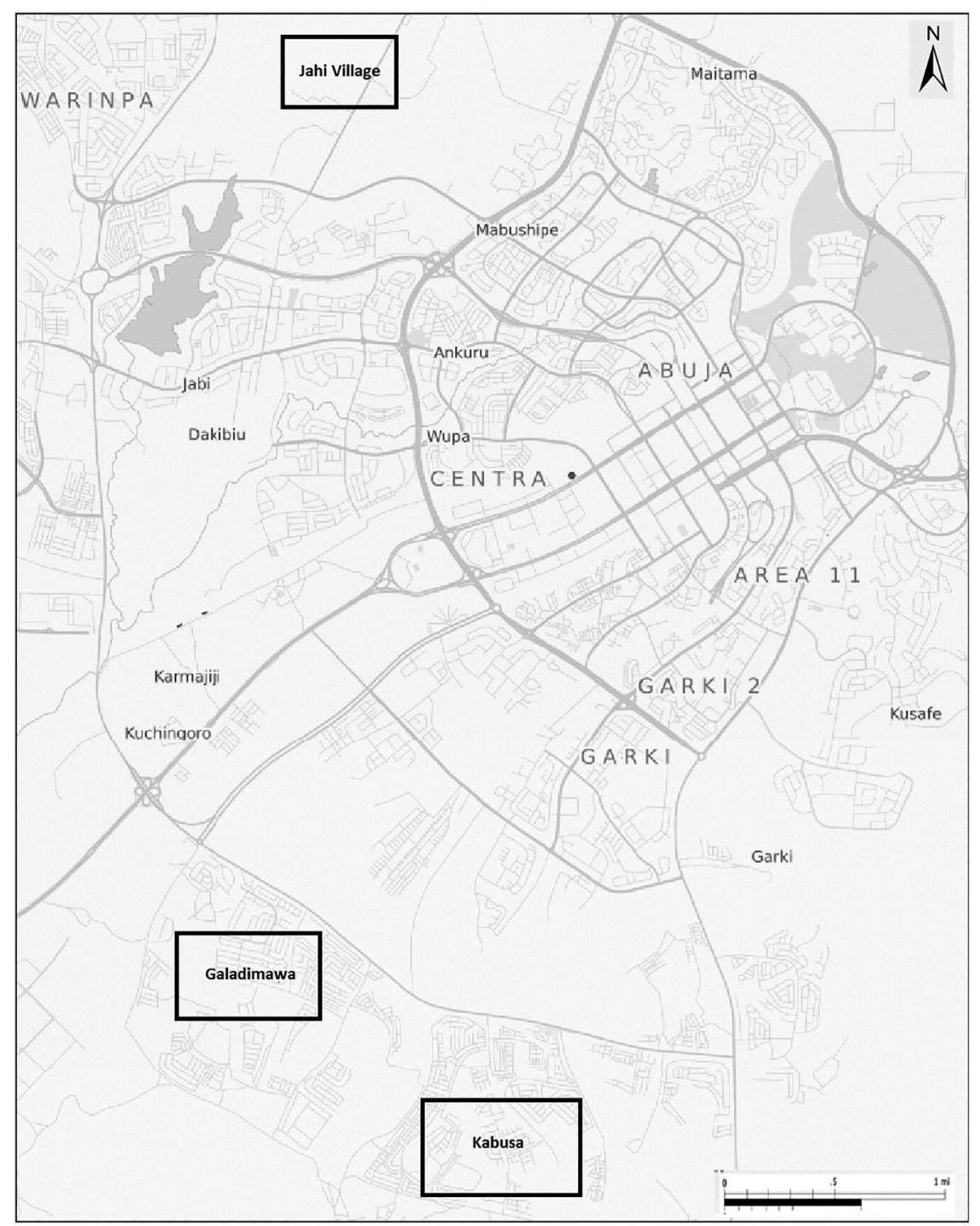

Figure 9.2 Abuja: location of interception transport surveys

Source: Own elaboration

The surveyed population is composed largely of young adults aged 20 to 40 (93\%), with males dominating the sample (59\%). This is an important feature to bear in mind, because it could significantly shape the interpretation of perceptions, practices and vulnerabilities. For example, lower presence of women in public spaces could reflect lower rates of labour-market participation or arise from social conventions restricting their circulation. Also 
of note is the fact that three quarters of respondents are Christian, with the remaining quarter stating that they are Muslim.

Income is a major influence on wellbeing. Socially vulnerable groups such as low-income populations are more susceptible to the negative externalities of urban transport and thus could be more deeply affected. Nearly half of respondents $(48 \%)$ reported earnings below the national minimum wage of 18,000 Naira/month (US\$90) (The Nation, 2015), with a larger comparative share of women in the lower-income bracket than men $(46 \%$ of women compared with $42 \%$ of men).

The relational dimension was examined through semi-structured interviews with 18 residents in total between the selected settlements in Abuja, and focused on how people interact with transport and its public-space character, provision of transport services and interaction with the state through transport. The subjective dimension permeates most of the information collected in the survey, since most of the variables have a subjective element, some more than others. The issue of freedom to move around and therefore the reliability of the system is very important for respondents. Because of limitations inherent to the survey, additional information was compiled to help shed light on planning and practice, challenges faced by current policies to increase wellbeing of urban populations through transport, and governance issues that might limit people's ability to influence transport services so they contribute more effectively to their wellbeing.

In this vein, a series of in-depth interviews was conducted (Figure 9.3) with three types of respondents identified with the help of our local research partner: public officials involved in urban transport planning and development, local academics and transport service providers. Seven interviews were conducted in Abuja. 


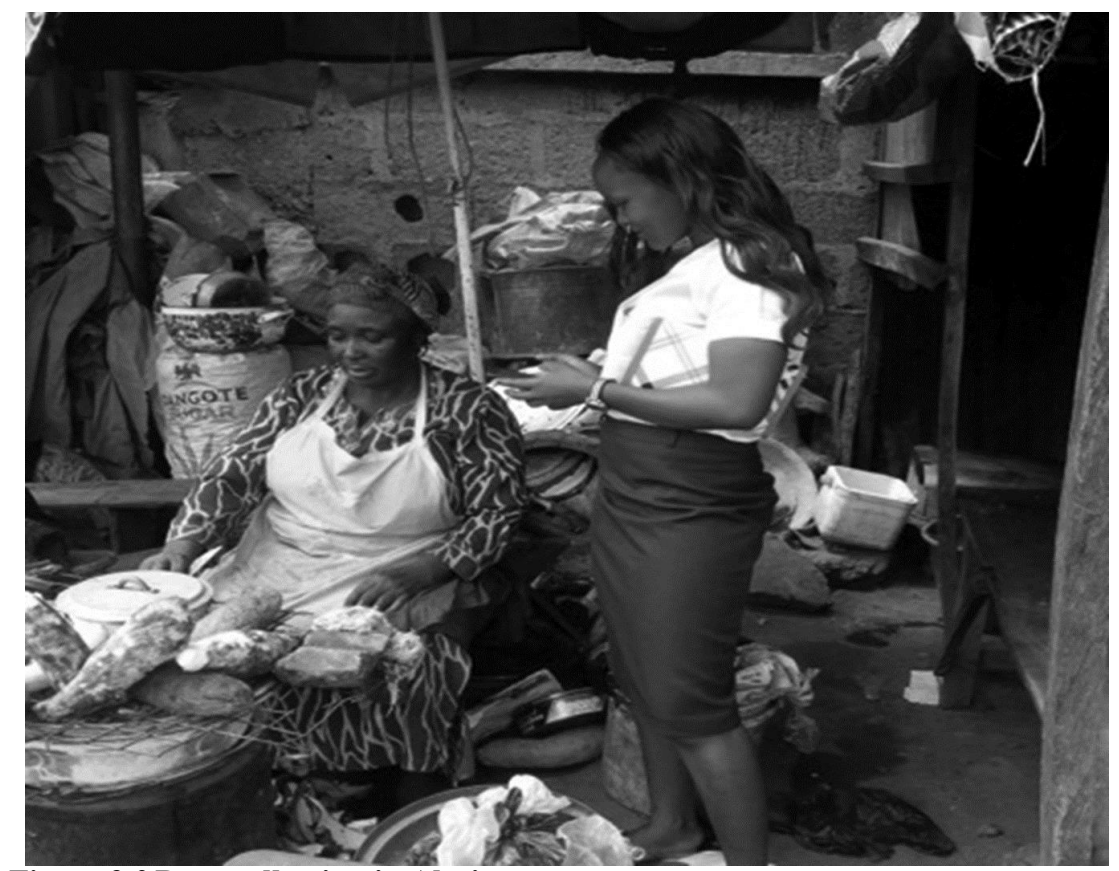

Figure 9.3 Data collection in Abuja

Photo: Odukogbe, 2015

\section{Abuja - a new capital still under construction}

Abuja is a post-colonial city. Created in 1976, the new federal capital sought 'to stand not only as a symbol of a new national consciousness but also as a vignette of the vision of the African city entertained if not by African planning then certainly by African decision makers' (Mabogunje, 1990: 146). International consultants submitted the Master Plan (1976-2000) to the Nigerian government in 1979. A Federal Capital Development Authority (FCDA) was set up to implement the Master Plan, and construction started in 1981. In 1985, the FCDA was brought under the authority of the Ministry of the Federal Capital. In 1991, the seat of government was moved there from Lagos, the main port and national commercial centre (Femi, 2012; Jibril, 2015).

The symbolism of Abuja goes beyond its power as a statement of pride and unity in a post-independence state. It was to be a counterpoint to Lagos, seen as a city in crisis, as reflected in traffic congestion and a failed system of land and urban development (Adeponle, 2013; Femi, 2012). Conceived as a crescent or horseshoe, Abuja's Master Plan was 'intended to regulate land use, transportation systems, infrastructure, housing and other services in a manner 
that recognized their interrelationships and spatial requirements' (Adeponle, 2013: 147). The Master Plan was to be developed in four phases over 25 years.

Contemporary Abuja differs from the Master Plan proposals in several ways that are interrelated and relevant to the current transport situation. First, the Plan proposed a maximum population of 3 million by 2000, with growth over and above this to be housed in designated satellite towns (Jibril, 2015). It is estimated to have currently a base population of more than 3 million people, but with the daily influx of commuters, its daytime population can rise to 7 or 8 million (Iro, 2007; Femi, 2012). A magnet for in-migration, at more than 8\% per annum, Abuja has one of the fastest population growth rates in Nigeria and among the fastest in Africa (Myers, 2011). Growth is faster in satellite settlements, which according to Abubakar and Doan (2010), are growing at about $20 \%$ per annum.

Second, while the Master Plan proposed a new city, the chosen location was not empty of people. It required the relocation of 845 villages (Adeponle. $\underline{2013}$ ). However, over time and driven by different political regimes, there has been some policy vacillation about their resettlement (and compensation) or integration into the Plan (Jibril, 2015). The outcome has been, on the one hand, the forced evictions of more than 800,000 people between 2003 and 2007 (Fowler et al., 2008) and on the other, along with the lack of planned housing provision, the growth of informal settlements in the city (ibid.; Adeponle. 2013).

Third, implementation has not advanced as planned. Phase 1 is largely completed, focusing mainly on government and private development. Subsequent phases demonstrate progressively less completion from phases 2 through 4 in which the lack of planned housing, infrastructure and transport are the most critical aspects. Nevertheless, the population continues to grow, so 'the present reality today shows an increase in the size of the FCC from the original 250 square kilometers to 1,123 square kilometres' (Jibril, 2015: 14). The result is acute housing shortages (Abdullahi and Aziz, 2010; Umoh, 2012), proliferation of informal settlements (Amba, 2010; Jibril, 2005), occupation of uncompleted buildings (Abubakar and Doan, 2010), inadequate supply of water and sanitation to the poor (Ilesanmi, 2006: Ojo, 2011) and traffic congestion (Abubakar, 2014).

Transport infrastructure was central to structuring the Master Plan, with the original vision for the city one of “... wide green belts separating neighborhoods of different social classes ... low-density and low-rise buildings with wide streets based on the expectation of the highly motorized population ...' (Mabogunje, 1992: 147). Each phase was bounded by largescale expressways, complemented by the presence of a road-connected system of satellite towns such as Idu (the major industrial site) and Dei-Dei (home of the international livestock market and the international building materials market). However, whilst road provision is $90 \%$ complete in Phase 1 , it is only respectively $35 \%, 25 \%$ and $5 \%$ completed in subsequent phases (Femi, 2012). 
The plan's pledge for a "provision of public transport mobility to residents who do not own cars" (Femi, 2012: 120) has not been implemented. This has resulted in congestion and the expansion of alternative informal-sector mass transit modes, and in increasing tensions among transport providers, as well as with Federal Capital Territory (FCT) bodies. Rail infrastructure planned in Phase 1 (Jibril, 2015) is only now being provided in the form of a light rail system (LRT). Similarly, a bus rapid-transit system (BRT) is being implemented, though without inclusive citizen participation and coupled with a ban in 2012 of commercial motorcyclists and mini-bus operators (Ebo, 2015). Some suggest that the current transport difficulties arise from the separation of transport policy under the auspices of the Transport Secretariat of the FCDA, and the provision of infrastructure in another part of the FCDA (Femi, 2012).

As shown in the next section, the result is that most motorized transport users resort to a range of informal and non-motorized transport modes.

\section{Mobility in Abuja}

This section presents the evidence on the transport-wellbeing relationship in its three dimensions: material, relational as an aspect of life and perceived, as applied to the three low-income settlements in Abuja (See example in Figure 9.4) that are the focus of the case study.

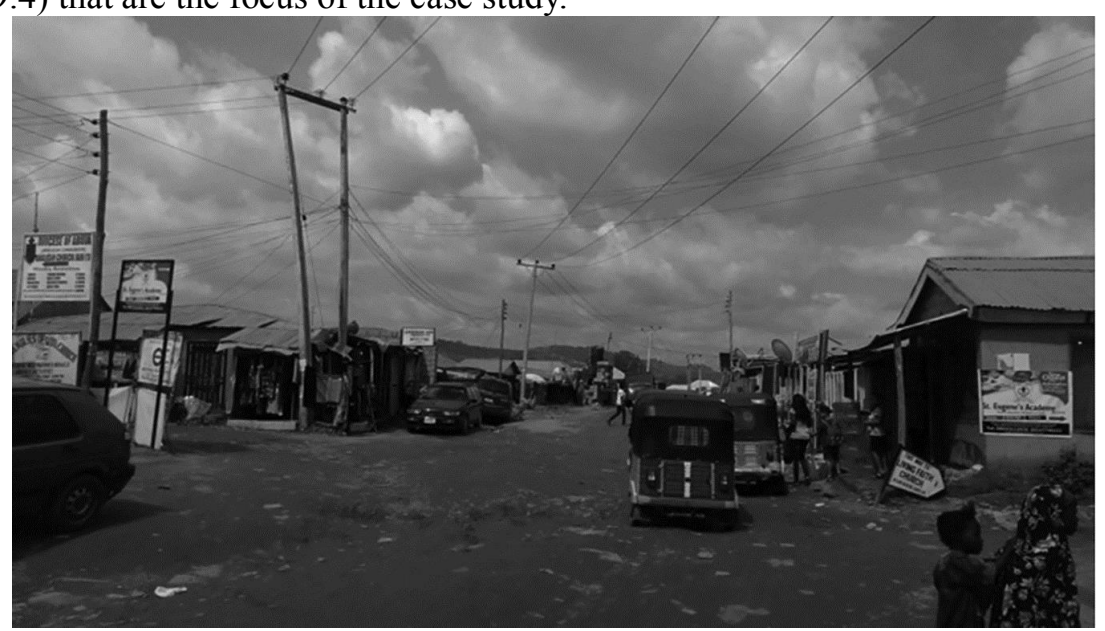

Figure 9.4 Jahi Village, Abuja

Photo: Odukogbe, 2015

The material dimension of wellbeing: individual and collective assets and accessibility 
A vast informal sector exists in Abuja, which currently employs two thirds of residents in the municipality and close to $80 \%$ in the larger FCT (FCT MDG Office, 2009). Acknowledging that this was a long-term reality in Nigeria, the Master Plan projected that $40 \%$ of jobs would be of an informal nature, and allowed space for informal businesses in designated locations (IPA, 1979; Abubakar, 2014). However, small-scale traders are often unable to afford rents, pushing them to hawking or using roadsides to sell their goods and services, with implications for daily mobility. Similar levels of informality are also present in transport services, particularly in satellite settlements such as those in this research. It is striking that most survey respondents use informal transport modes such as okada (motorcycle taxis), danfo (minibuses), keke napep (rickshaws) and shared taxis (56\% of the total sample). A total of 57\% of female respondents resort to these modes, with okada the most frequent one, while $70 \%$ of respondents who said to be unemployed also use informal modes. Non-motorized transport represents the second largest category, with higher dependency on this among certain social groups. For example, $37 \%$ of women complete most of their trips on foot, and between $34 \%$ and $40 \%$ of people in the three lowest income ranges also walk for most of their trips.

A quadrant analysis (Currie and Delbosc, 2011) shows that for a significant share of the sample (39\%) it is both difficult and important to access transport without depending on others (Figure 9.5). Furthermore, for $55 \%$ of the sample this is an important feature of their mobility, which can be interpreted as a potential difficulty in their daily travel practices.

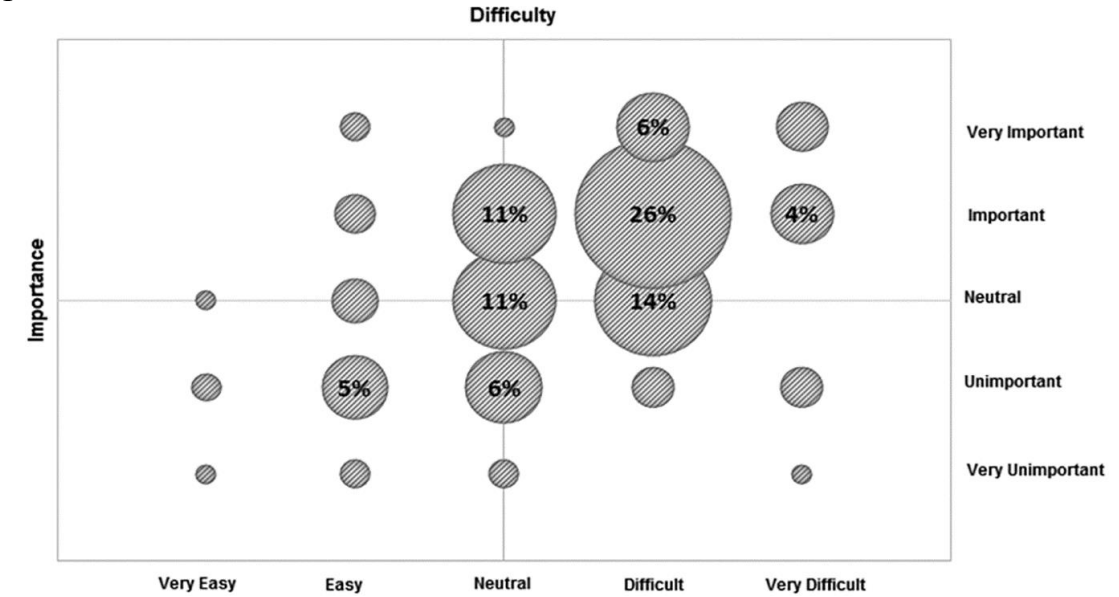

Figure 9.5 Using transport without depending on others (\% of respondents)

Source: Own elaboration based on field data

A substantial majority (79\%) of those surveyed said that they had difficulties in accessing productive activities. Lower-income respondents are mainly users of non-motorized and informal means of travel, which tend to be slower, more polluting and more uncomfortable than formal modes, with 
knock-on effects on users' physical wellbeing and availability of time for other activities. However, people reporting difficulties also have a higher mean income, which also has implications for the location of such opportunities. This calls for further reflection regarding expectations of different social groups and the subjective nature of wellbeing analysis. It also requires higher considerations for decision-making in balancing mobility conditions for different social groups and increasing expectations of low-income populations.

A closer examination of the data summarized in Table 9.1 reveals that people who do not perceive difficulties in accessing transport for productive activities benefit from a larger local supply of informal transport and tend to walk less, despite having lower average incomes, while tending to travel more to other satellite areas rather than to the centre of Abuja. An analysis of the average percentage of individual monthly income spent on a single trip shows two dominant categories of expenditure: those who spend $1 \%$ of their income or less (39\% of the sample), and those who spend more than $5 \%$ (34\% of the sample). Among respondents in the first category, the share of non-motorized travel is approximately $50 \%$ of all trips. A higher proportion of male respondents said they experienced difficulties, a perception that can be partly explained by the fact that men tend to perceive themselves as breadwinners in the household.

Table 9.1 Perceived difficulties in accessing economic opportunities because of transport

\begin{tabular}{|c|c|c|c|c|c|c|}
\hline \multirow[b]{2}{*}{ Factor } & \multicolumn{2}{|c|}{$\begin{array}{c}\text { Economic } \\
\text { opportunities }\end{array}$} & \multicolumn{2}{|c|}{$\begin{array}{l}\text { Health and } \\
\text { education }\end{array}$} & \multicolumn{2}{|c|}{ Religious facilities } \\
\hline & Yes & No & Yes & No & Yes & No \\
\hline Share of respondents & $79 \%$ & $21 \%$ & $47 \%$ & $53 \%$ & $20.50 \%$ & $79.50 \%$ \\
\hline Mean income (US\$) & 144.4 & 104.1 & 143 & 128 & 137.4 & 136 \\
\hline Average age & 30.05 & 31.39 & 29.2 & 31.3 & 30.5 & 30.3 \\
\hline \multirow{2}{*}{ Mean level of education } & \multirow{2}{*}{\multicolumn{2}{|c|}{ Secondary Secondary }} & \multicolumn{2}{|c|}{ Secondar Secondar } & \multicolumn{2}{|c|}{ Secondar Secondar } \\
\hline & & & y & y & $y$ & $y$ \\
\hline Gender & 69\% Male & $58 \%$ Male & $55 \%$ & $76 \%$ & $68 \%$ & $67 \%$ \\
\hline & & & Male & Male & Male & Male \\
\hline Mean trip cost/income & $1.40 \%$ & $2.60 \%$ & $1.80 \%$ & $1.50 \%$ & $2.10 \%$ & $1.50 \%$ \\
\hline $\begin{array}{l}\text { Availability of } \\
\text { opportunities }\end{array}$ & 3.1 & 2.64 & 3.1 & 2.8 & 2.64 & 3.09 \\
\hline
\end{tabular}




\begin{tabular}{|c|c|c|c|c|c|c|}
\hline $\begin{array}{l}\text { Travel cost score (out of } \\
\text { 5) }\end{array}$ & 3.21 & 2.92 & 3.39 & 3.31 & 3.35 & 3.35 \\
\hline $\begin{array}{c}\text { Travel time score (out of } \\
5 \text { ) }\end{array}$ & 3.29 & 3.01 & 3.48 & 3.33 & 3.26 & 3.44 \\
\hline
\end{tabular}

Availability of employment is measured on a scale from 1 to 5 where 1 is very low, 3 is indifferent and 5 is very high

Source: Own elaboration based on field data

Traditional transport analyses rarely explore accessibility beyond travel to work. Although other trips such as leisure, retail and visits to friends and family are very relevant for material wellbeing, interpreting this dimension involves availability of opportunities to allow full participation in society and a rewarding life depending on individual interests and priorities. For $64 \%$ of respondents, employment is not easily available, rating it as average or below. By contrast, a large majority believe that education, shops and leisure are easily available at the city-scale, suggesting that transport may be facilitating their access to these.

The ability to get on and off a means of transport is an important feature for most respondents and is related both with the physical conditions of people and transport features. Nearly $60 \%$ find difficulty in getting on and off particular transport modes. This is also related with social identities and conventions. Women find it difficult to get on and off okadas and keke napep, which according to interviewees is related to the customary sitting position in the motorcycle taxis and the limitations of traditional clothing for riding this type of vehicle. Older adults also perceive these difficulties in their daily mobility, and it is one of the higher-scoring transport features among this group.

Another material dimension of wellbeing relates to transport affordability. Interestingly, despite the sample of respondents being overwhelmingly lowincome when compared with average incomes and the legal minimum wage, affordability would not appear to be an explanatory variable in preventing users from gaining access to a range of opportunities. By contrast, the amount of time spent travelling scores negatively, showing that respondents place a premium on spending less time in transport. This might reflect the trade-off against cost for some of those walking and/or taking non-motorized modes of transport, which almost invariably take longer. Not surprisingly, higher purchasing power leads to better transport affordability, particularly in motorized modes. This entails class inequalities in the access to different types of transport and the ability of different social groups to appropriate and exercise a right to the city. Pockets of congestion and concentration of infrastructure and traffic can have localized effects that increase inequalities in the quality of the environment. 
One of the main issues to consider in the material dimension of wellbeing is the quality of the natural and built environment. Residents in Abuja appreciate the fact that the main streets are laid out according to a plan, and regularly maintained. However, this view contrasts with the recommendations made by respondents when asked what could be done to improve the transport system, as reported in Table 9.2 (see the section on the subjective dimension later in this chapter). There, respondents highlighted quality of the road network as a number one priority for improvement. This can be interpreted as referring largely to neighbourhood streets, rather than the citywide network, given deficiencies in maintaining the local road network.

The relational dimension: access to social interactions, security and opportunities for full participation in society

The relational dimension of wellbeing was examined mainly through semistructured interviews and focused on how people interact with transport, how transport is provided and how people interact with the state. Respondents perceive the state as enabling people to access transport to interact among themselves, practice their religious beliefs and use public space. A large share expressed dissatisfaction with the difficulties they face (see Table 9.1). For example, $20 \%$ of respondents said that they have transport difficulties in accessing religious facilities. Males are more acutely affected both in accessing religious facilities and reaching family members. When this is correlated with availability of religious activities, the score is negative (just over 2).

Evidence from the relational dimension shows that transport can play a significant role in enabling both mobility and the appropriation of space by citizens to facilitate their participation in social groups and interactions. Interestingly, no one reported difficulties in accessing their social connections. Adequate and reliable transport, especially at times when people socialize, can help increase relational wellbeing. The evidence also calls for complementarity between transport policies and policies from other sectors such as land use and public space.

Another important element to highlight is security in relation to crime and safety from road accidents. The availability of night transport is perceived as being both important for respondents and a source of difficulty. Most respondents feel that it is important that transport provides them with some security, particularly in relation to terrorism and crime. People feel more secure in Abuja than in the satellite locations. The availability of transport at times when crime is higher, or when people perceive higher vulnerability to it, is a relevant difficulty for more than $75 \%$ of the sample (Figure 9.6), with nearly $72 \%$ of respondents highlighting availability at night as important. This can be a hindering element for individual freedoms to move around and meet people. Supply under adequate conditions of security is a responsibility of the 
state and can be complemented with availability of services and infrastructure that can increase perception of security at night.

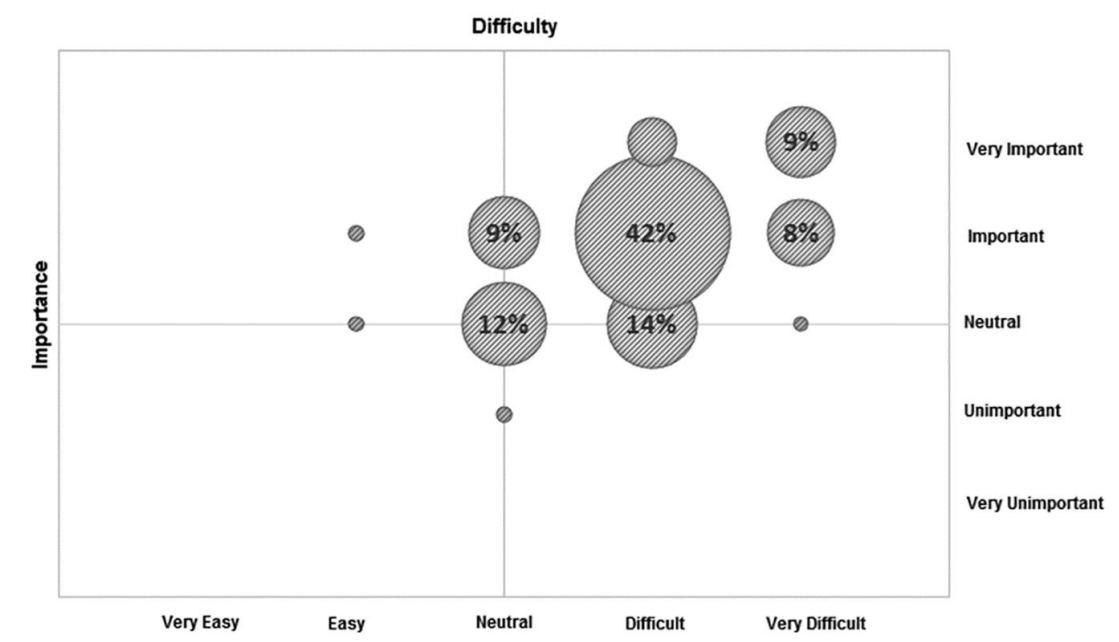

Figure 9.6 Transport availability at night (\% of respondents)

Source: Own elaboration based on field data

Crime and terrorism can govern travel practices and access to opportunities, relations and overall satisfaction of transport. Young women are particularly concerned about protection from crime, and they find it more difficult to feel safe when using transport. There are significant differences as to how people with different social identities perceive terrorism. Of the $24 \%$ for whom feeling safe from terrorism is both important and difficult, nearly $65 \%$ are women. The mean score of the perception of safety from crime at the neighbourhood level (3.24 out of 5) is lower than at the city scale (3.63 out of 5 ). This reveals the relevance of crime as a hindering factor for local mobility and the relevance of urban infrastructure and facilities at the local level that can increase perceptions of security and reduce difficulties in feeling safe in daily travel practices. The higher city-scale score could be related to better quality of the built environment and greater presence of security services resulting from the high concentration of public agencies, including national ministries, and foreign diplomats.

In relation to traffic safety, there is a strong perception that traffic is chaotic so that the second most frequent recommendation for authorities is to enforce better compliance with rules (see Table 9.2 in the following section). This is at the same time a relational and subjective dimension, which is worth highlighting and exploring further.

What emerged from interviews with public officials in departments responsible for both the long-term planning and day-to-day operation of Abuja's public transport is that there are entrenched institutional challenges to 
improving planning and relationships with the population. At the core of this is the lack of a metropolitan authority for managing transport in the FCT. Transport planning is one of many central government functions, and is therefore more susceptible to slow bureaucratic procedures and political meddling. A bill recently brought to the National Assembly for the creation of a metropolitan authority for the FCT that resembles the structure of Lagos' Metropolitan Transport Authority (LAMATA) has been under consideration for more than two years, with poor prospects, partly because of limited political support. Without the legal authority and associated legitimacy, many technical decisions can be overturned by political interests.

According to interviewees, conditions are not conducive for building and consolidating capacity within public agencies involved in urban transport planning and management. There is a need to put a 'structure in place to attract talent currently being drawn to the private sector or going abroad' (M, 39, CS, MA). ${ }^{2}$ Without strong institutions, it will become very difficult to assess impacts of transport developments, constraining the understanding of local officials and planners of the priorities for improving transport, particularly for Abuja's poor. A stronger conceptual approach is required to understand the contribution of transport to wellbeing that can counterbalance traditional economic rationale underpinning decision-making in transport planning. Such traditional rationale is closely connected to the evidence of priorities from the perspective of public officials: higher advocacy for infrastructure development for transport; development of a feeding routes programme for the BRT and LRT projects; redefinition of subsidies currently in place to reach target populations; and integration with different forms of formal and informal transport, including providers of interstate transport services. These largely technical issues contrast with the quantitative evidence collected in the case studies, revealing the need for more frequent and open interactions between transport planners and decision-makers on the one hand and the population on the other, particularly in satellite settlements. Development of an integrated approach to wellbeing that can inform transport policy can contribute to positive change in the approach from planners and decision-makers to transport investments and development, recognizing the limitations of transport interventions in addressing multiple sub-dimensions of wellbeing discussed in this chapter.

\section{The subjective dimension: freedom, satisfaction and autonomy}

The subjective dimension is the third element in our framework. For respondents, the freedom to move around, and therefore the reliability of the system, are very important. A general perception is that the transport system fails to provide them with a reliable means of moving quickly between places at times that suit them, thus restricting their autonomy. Among 19 respondents ( $6 \%$ of the total) there is a belief that the transport system has prevented them 
from accessing key places, such as the city centre, or has not allowed them to establish and maintain social interactions. Although small compared with the sample size, it is nonetheless a worrying finding. This relates to earlier concerns regarding the subjective perceptions of people in different social positions about what they can expect from transport investments. Results consistently suggest that lower-income and other socially vulnerable populations have lower expectations than better-off groups; targeted considerations in transport policy and decision-making are required to deliver a more equitable response to differentiated needs and to balance future expectations.

The issue of autonomy and liberty to move in urban space can be related to difficulties with spatial and temporal autonomy, affecting access to opportunities and enjoyment of life. These issues are perceived as being more important, though transport is perceived as having a limited ability to address subjective needs of reliability, independence and liberty. More than $64 \%$ of respondents find it difficult to reach places quickly with transport; $70 \%$ perceive difficulties in finding transport services and alternatives; $36 \%$ find difficulties in changing transport services; and $65 \%$ have difficulties moving at any time (Figure 9.7).

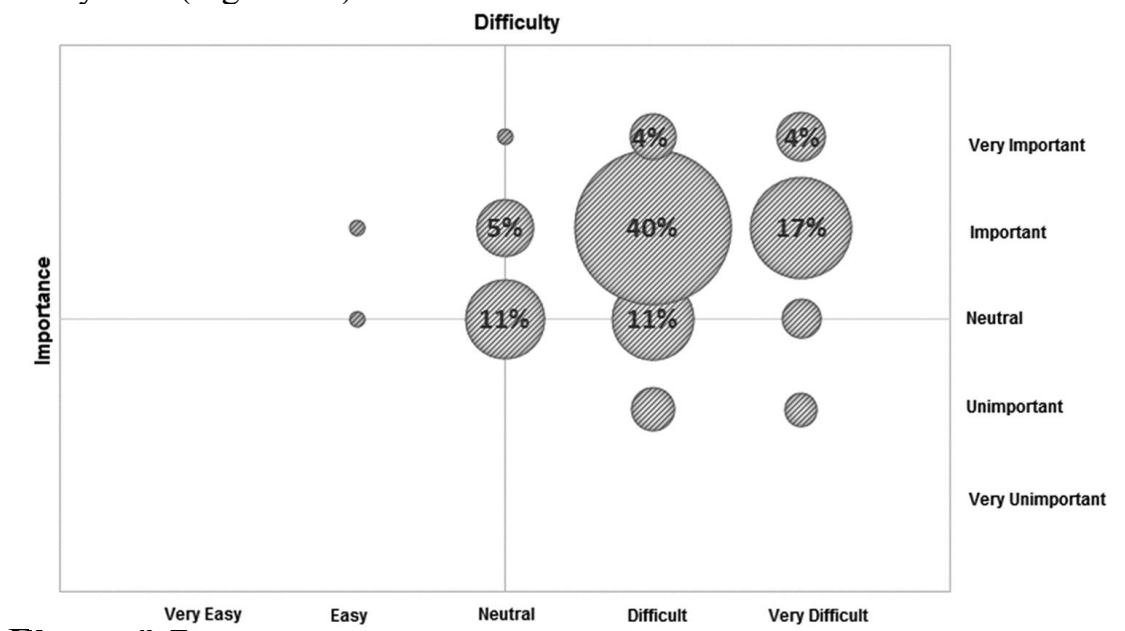

Figure 9.7 Ability to move at any time (\% of respondents) 


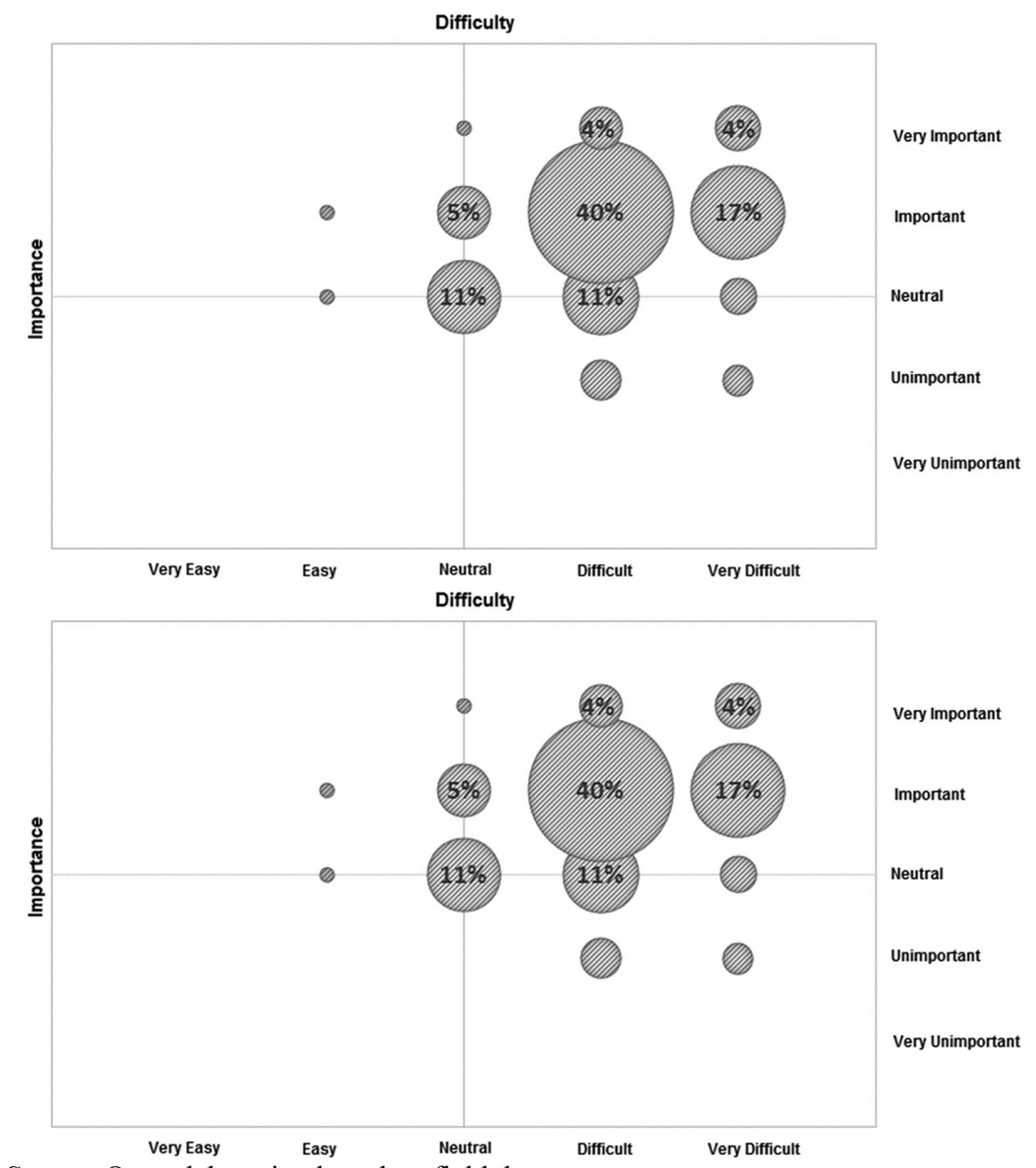

Source: Own elaboration based on field data

For respondents in Abuja, the city's transport system offers more spatial autonomy and reliability compared with the other two Nigerian cities examined in the larger research project, although freedom to move at different times of the day is perceived as a constraint. Weekends and festive seasons are frequent references to times when transport is insufficient to allow expected levels of travel. This is especially true in relation to social interactions; these periods are the most relevant for relational wellbeing because it is the time when people tend to socialize. Something similar occurs with the loss of spatial autonomy. This affects all dimensions of wellbeing because the inaccessibility of specific areas can restrict the capacity of individuals and social groups to participate in activities centralized in space. Lower subjective perceptions of the effects of transport on personal and collective liberties and 
empowerment are intimately linked with travel choices as to when to travel, where and with what means, central variables in transport planning and policy.

Respondents were asked about their top three priorities for public investment or actions to improve the transport system (Table 9.2). The results reveal a limited awareness of what the government can do to improve transport.

Table 9.2 Perceived priorities for public investment/action at the city level

\begin{tabular}{||l|r||}
\hline \multicolumn{2}{|c||}{ Priorities for public investment/action } \\
\hline \hline Better bus stop/interchange & Percentage of responses \\
Better roads & $1 \%$ \\
Cheaper transport fare & $39 \%$ \\
Less crowded vehicles & $5 \%$ \\
Less noise/air pollution & $2 \%$ \\
More availability across city/more frequent services & $4 \%$ \\
Other & $2 \%$ \\
Pedestrian pavement footpath & $8 \%$ \\
Reduced road congestion & $8 \%$ \\
Street lights & $3 \%$ \\
Traffic order/better compliance & $4 \%$ \\
\hline
\end{tabular}

Source: Own elaboration based on field data

\section{Conclusion}

In a context such as Abuja's, marked by spatial and social differences embedded in a post-colonial modernist vision of development, and where issues of social diversity, spatial segregation and informality are often overlooked, a reflection on the wider implications of urban transport can contribute to inform urban transport development and policy. This is particularly true in relation to concerns often considered 'beyond' transport planning such as security, autonomy and freedom.

The evidence outlined here is unique in the Nigerian context, and not easily found in the literature concerned with transport and wellbeing in a Global 
South context. When considered together, the dimensions and sub-dimensions of wellbeing related to urban transport offer a deeper understanding of the dynamic relation between mobility and the wellbeing of residents and workers in Abuja. The framework provides a way to outline the evidence, allowing different interrelated variables to 'dialogue' with each other as in the case of access to opportunities and dominant socio-economic characteristics and perceptions. Indices are designed so they can be easily interpretable and interchangeable so the information can be accessible at most levels of urban transport development.

Respondents in Abuja's low-income satellite towns have very limited expectations of what the government can do to improve transport, highlighting infrastructure-related issues as their main priority. This contrasts with the results of our analysis of difficulties and importance of transport features, which highlight issues such as security, connectivity, local accessibility and autonomy as being more pressing. This is linked with the priorities of the planning system and the level of participation that it involves. Having a predominantly top-down approach, the plans for the city - outlined more than three decades ago - do not acknowledge the needs and preferences of the population arising from its considerable social, spatial and economic diversity.

Results suggest a mismatch between the actions and proposals by the state and the priorities for improving wellbeing of local citizens. On the one hand, the priorities revealed by both planners and decision-makers question the traditional transport system in practice in Nigeria. The ideological preference for the private vehicle and the strong focus on infrastructure and modernity do not respond equitably to the needs for improving wellbeing. In Nigeria, the issue of congestion is one of the most relevant by-products of such traditional systems, and it has a profound effect on the distributional impacts of daily mobility practices for different social groups. On the other hand, the study of wellbeing in its multiple dimensions calls for attention to issues frequently overlooked from mainstream transport planning. Furthermore, the ideological underpinnings of the wellbeing framework that supports fostering not only accessibility but the relational and subjective contributions of transport to people's lives contribute to debates around current approaches to transport development and decision-making and the role of mobility in human development.

Scaling up a methodology such as the one we propose, coupled with greater involvement of the local population in identifying indicators that build on their own interpretations of the contribution of transport to their wellbeing considering the subjective beliefs and perceptions of people at different social positions - could go a long way in opening a more fluid and constructive interaction between the state and civil society. This can also offer a broader and deeper understanding of the nature of wellbeing as it relates to transport users than that offered by civil servants and transport experts. The formulation of plans is based on knowledge that, however sophisticated, can always be 
challenged and refined by the rich experience of people who use a system daily, and probably more regularly than those who make key decisions that can profoundly affect their lives.

\section{Notes}

\section{References}

Abdullahi, B.C., and Aziz, A.W. (2010). Nigeria's Housing Policy and Public-Private Partnership (PPP) Strategy: Reflections in Achieving Home Ownership for Low-Income Group in Abuja, Nigeria. 22nd International Housing Conference, ENHR, July, pp. 4-7.

Abubakar, I.R. (2014) Abuja city profile. Cities 41, 81-91.

Abubakar, I.R., and Doan, P.L. (2010). New Towns in Africa: Modernity and/or Decentralization. 53rd Annual Meeting, African Studies Association, San Francisco, USA.

Adeponle, B.J. (2013) The integrated city as a tool for sustainable development. Journal of Educational and Social Research 3 (5), 145-153.

Alkire, S. (2015). Well-being, Happiness, and Public Policy. Centre for Bhutan Studies \& GNH Research. Thimphu, Bhutan

Amba, K. E. (2010). Unmasking the Barriers to Citizen Participation in Political Processes in Abuja, Nigeria. Report. University of Guelph. Ontario.

Australian Government (2010). Australian Social Inclusion Board. Annual Report, Commonwealth of Australia, Canberra.

Banister, D. and Bowling, A. (2004) Quality of life for the elderly: The transport dimension. Transport Policy 11 (2), 105-115.

Becker, G.S. (1962) Investment in human capital: A theoretical analysis. The Journal of Political Economy 70 (5) 9-49.

Beckman, L.J. (1976) Alcoholism problems and women: An overview. In: Greenblatt, M. and Schuck, M.A. (eds.), Alcoholism Problems in Women and Children, 65-69. New York, NY: Grune and Stratton.

Bloch, R. and Papachristodoulou, N. (2014) Urbanisation Research Nigeria (URN) Framework and Plan. London, UK: ICF International.

Boarini, R., Johansson, Å., and d'Ercole, M.M. (2006). Alternative Measures of Wellbeing. OECD. Paris

Camfield, L. and Skevington, S.M. (2008) On subjective wellbeing and quality of life. Journal of Health Psychology 13 (6), 764-775.

Cervero, R.B. (2013) Linking urban transport and land use in developing countries. Journal of Transport and Land Use 6 (1), 7-24. 
Currie, G. and Delbosc, A. (2011) Exploring Transport Issues. In Currie, G. (ed.), New Perspectives and Methods in Transport and Social Exclusion. Emerald Bingley, UK.

Delbosc, A. and Currie, G. (2011) The spatial context of transport disadvantage, social exclusion and wellbeing. Journal of Transport Geography 19 (6), 11301137.

Dodge, R., Daly, A.P., Huyton, J. and Sanders, L.D. (2012) The challenge of defining wellbeing. International Journal of Wellbeing 2 (3), 222-235.

Ebo, I. (2015). Planning for Exclusion in Abuja. Available at: www.opendemocracy.net /opensecurity/ifeoma-ebo/planning-forexclusion-in-abuja (accessed March 2016).

Falola, T. (1996). "Africa in Perspective" in Africa Now: People, Policies and Institutions. Ed. S Ellis. London: Heinemman.

FCT MDG Office (2009) FCT MDG baseline 2009: Employment. Federal Capital Territory Millennium Development Goals Office. Available at: www.mdgfctabuja.net/Baseline10/Employment.aspx (accessed June 2015).

Femi, S.A.G. (2012) Characterization of current transportation challenges in the federal capital territory, Nigeria. Journal of Sustainable Development 5 (12), 117.

Fowler, D, Huchzermeyer, M., Idahosa, J (2008) The Myth of the Abuja Master Plan: Forced Evictions as Urban Planning in Abuja, Nigeria. The Centre on Housing Rights and Evictions. Geneva, Switzerland ).

Home, R. K. (1983). Town planning, segregation and indirect rule in colonial

Nigeria. Third World Planning Review, 5(2), 165.

Ilesanmi, I. (2006). Pre-feasibility Assessment of Decentralised Sanitation Systems for New Satellite Settlements in Abuja. Cuvillier. Abuja, Nigeria

IPA (International Planning Associates) (1979) The Master Plan for Abuja, the New Federal Capital of Nigeria. FCDA, Abuja: Nigeria.

Iro, I. (2007) Demographic pressure and the application of GIS in land reforms: The case of restoration of Abuja master plan and sanitization of cadastral and land registry. In Proceedings of map middle east conference on GIS development, Dubai, UAE.

Jibril, I.U. (2015). Planning and Land Administration Challenges in Developing New Cities: The Abuja Experience in Nigeria. FIG Working Week 2015: From the Wisdom of the Ages to the Challenges of the Modern World. Sofia, Bulgaria, 17-21 May.

Jones, P. and Lucas, K. (2012) The social consequences of transport decision-making: Clarifying concepts, synthesising knowledge and assessing implications. Journal of Transport Geography 21, 4-16.

La Placa, V., McNaught, A. and Knight, A. (2013) Discourse on wellbeing in research and practice. International Journal of Wellbeing 3 (1), 116-125.

Levy, C. (2013) Travel choice reframed: 'deep distribution' and gender in urban transport. Environment and Urbanization 25 (1), 1-17. 
Lucas, K. (2012) Transport and social exclusion: Where are we now? Transport Policy 20, 105-113.

Mabogunje, A.L. (1968) Urban land use problems in Nigeria. Institute of British Geographers Special Publication 1, 203-218.

Mabogunje, A.L. (1990) Urban planning and the post-colonial state in Africa: A research overview. African Studies Review 33 (2), 121-203.

Mabogunje, A.L. (1992) New initiatives in urban planning and management in Nigeria. Habitat International 16 (2), 73-88.

Manderson, L. (2005) The social context of wellbeing. In: Manderson, L. (ed.), Rethinking Wellbeing. Netley, South Australia: Griffin Press.

McFarlane, C. (2008) Governing the contaminated city: Infrastructure and sanitation in colonial and post-colonial Bombay. International Journal of Urban and Regional Research 32 (2), 415-435.

Mollenkopf, H., Marcellini, F., Ruoppila, L., Flaschentrager, P., Gagliardi, C. and Spazzafumo, L. (1997) Outdoor mobility and social relationships of elderly people. Archive of Gerontology and Geriatrics 24, 295-310.

Mollenkopf, H., Baas, S., Marcellini, F., Oswald, F., Ruoppila, I., Szeman,

Z., Tacken, M., Wahl, H. Mobility and Quality of Life: Enhancing Mobility in Later Life. ISO Press, Amsterdam (2005)

Myers, G.A. (2011) African Cities: Alternative Visions of Urban Theory and Practice. London, UK: Zed Books.

The Nation. (2015). Beyond Minimum Wage. Available at: http://thenationonlineng.net/beyond-minimum-wage/ (accessed May 2015).

Office for National Statistics (2014). Measuring National Wellbeing, Life in the UK, 2014. Database. Available at: http://webarchive.nationalarchives.gov.uk/20160105160709/http://ons.gov. uk/ons/rel/wellbeing/measuring-national-wellbeing/life-in-the-uk 2014/index.html (accessed 14 March 2015).

Odukogbe, S. (Photographer). (2015, March 20). Fieldwork photographs: Transport and wellbeing in Urban Nigeria [digital image compendium]. Private Archive. Development Planning Unit, University College London. London.

Ohnmacht, T., Maksim, H. and Bergman, M.M. (eds.). (2009) Mobilities and Inequality. Aldershot: Ashgate.

Ojo, V.O. (2011). Customer satisfaction: A framework for assessing the service quality of urban water service providers in Abuja, Nigeria. Doctoral dissertation, (C) Ojo, VO.

Oviedo Hernandez, D., and Titheridge, H. (2015) Mobilities of the periphery: Informality, access and social exclusion in the urban fringe in Colombia. Journal of Transport Geography 55 (1), 152-164.

Pacione, M. (2003) Urban environmental quality and human wellbeing - a social geographical perspective. Landscape and Urban Planning 65 (1), 19-30. 
Solanke, M.O. (2013) Challenges of urban transportation in Nigeria. International Journal of Development and Sustainability 2 (2), 891-901.

Spinney, J.E., Scott, D.M. and Newbold, K.B. (2009) Transport mobility benefits and quality of life: A time-use perspective of elderly Canadians. Transport Policy 16 (1), 1-11.

Stanley, J.K., Hensher, D.A., Stanley, J.R. and Vella-Brodrick, D. (2011) Mobility, social exclusion and wellbeing: Exploring the links. Transportation Research Part A: Policy and Practice 45 (8), 789-801.

Stanley, J., \& Lucas, K. (2008). Social exclusion: what can public transport offer?. Research in transportation economics, 22(1), 36-40.

Stanley, J., \& Vella-Brodrick, D. (2009). The usefulness of social exclusion to inform social policy in transport. Transport Policy, 16(3), 90-96.

Stiglitz, J., Sen, A., \& Fitoussi, J. P. (2009). The measurement of economic performance and social progress revisited. Reflections and overview. Commission on the Measurement of Economic Performance and Social Progress, Paris.

Swanson, M. (1977) The sanitation syndrome: Bubonic plague and urban native policy in the Cape Colony, 1900-1909. Journal of African History 18, 387-410.

Titheridge, H., Christie, N., Mackett, R., Hernández, D.O., and Ye, R. (2014) Transport and Poverty. A Review of the Evidence. Report, University College London, London, UK. Available at: https://www.ucl.ac.uk/transportinstitute/pdfs/transport-poverty (accessed May 2015).

Umoh, N.N.E. (2012) Exploring the Enabling Approach to Housing Through the Abuja Mass Housing Scheme. Doctoral dissertation, Massachusetts Institute of Technology, Cambridge, MA.

UNDP (1990). Human Development Report 1990. Oxford University Press, New York

UN-HABITAT (2013) Planning and Design for Sustainable Urban Mobility. Global Report on Human Settlements. Nairobi, Kenya.

van Lindert, P. (2016). Rethinking urban development in Latin America: A review of changing paradigms and policies. Habitat International, 54, 253-264.

Van Wee, B., \& Geurs, K. (2011). Discussing equity and social exclusion in accessibility evaluations. European Journal of Transport and Infrastructure Research, 11(4).

Vella-Brodrick, D. (2011) Contemporary perspectives on wellbeing, In Currie, G. (ed.), New Perspectives and Methods in Transport and Social Exclusion. Emerald. Bingley, UK.

Vella-Brodrick, D. and Delbosc, A. (2011) Measuring wellbeing, In Currie, G. (ed.), New Perspectives and Methods in Transport and Social Exclusion. Emerald Bingley, UK.

Wachs, M. (2010) Transportation policy, poverty and sustainability. TRR 2163, 5-12.

White, S.C. (2010) Analysing wellbeing: A framework for development practice. Development in Practice 20 (2), 158-172. 
${ }^{1}$ This is part of the 'Urbanization Research Nigeria' (URN) Programme (2013-2017), by a consortium coordinated by ICF International (Bloch and Papachristodoulou, 2014). URN is funded by the UK government's Department for International Development (DFID). Quantitative data were collected in collaboration with a local consulting firm, STO Associates.

2 Identification of interviewees: male/female (M/F), age, occupation: civil servant (CS), academia (A), private sector (PS), municipal authority (MA), national government $(\mathrm{NG})$ 